\title{
A propósito de la epidemia meningocóccica chilena (1941-1942): El niño con shock séptico hace 80 años desde la perspectiva médica y social
}

\section{About the Chilean meningococcal epidemic (1941-1942): the children with septic shock 80 years ago from a medical and social perspective}

\author{
Alejandro Donoso F. ${ }^{a}$, Daniela Arriagada S. ${ }^{a}$
}

aUnidad de Paciente Crítico Pediátrico. Hospital Clínico Metropolitano La Florida. Santiago. Chile

Recibido: 31 de enero de 2020; Aceptado: 29 de marzo de 2020

¿Qué se sabe del tema que trata este estudio?

Diversas epidemias ocurrieron en Chile en el siglo XX constituyéndose en un gran desafío para los pediatras y el equipo sanitario nacional. Una de las más relevantes fue la epidemia de la enfermedad meningocóccica.
¿Qué aporta este estudio a lo ya conocido?

Permite conocer el enfoque terapéutico realizado, apreciándose como diversas medidas fueron exitosas en lograr su objetivo. Esta crisis sanitaria originó el crecimiento y desarrollo del sistema de salud chileno, lo que cobra valiosa importancia en el escenario actual.

\footnotetext{
“En recuerdo del Dr. Enrique Fanta Núñez (1925-2019) quien fue uno de los que continuó con esta historia...."
}

\section{Resumen}

En nuestro país, la enfermedad meningocóccica presenta una baja endemia y alta letalidad, con existencia de brotes epidémicos, algunos de ellos de carácter histórico, como el acaecido durante la primera mitad del siglo pasado. La acción de un grupo de médicos, pioneros en los aspectos clínicos, de investigación y docencia, junto al personal de salud que constituía su equipo, inmersos en una política pública sanitaria exitosa, permitieron consolidar el cuidado necesario del niño enfermo de esta grave patología, como también de muchas otras, posibilitando así el desarrollo de una propuesta estructurada y científica a la luz del conocimiento disponible en aquella época. Por ello, luego de 80 años, es importante revisar los diversos aspectos clínicos, fisiopatológicos y terapéuticos, además del contexto hospitalario y social de esta exitosa historia del sistema de salud público chileno.
Palabras clave: Enfermedad meningocóccica; shock séptico; pediatras; historia pediatría; epidemia 


\begin{abstract}
In our country, meningococcal disease has a low endemic and high lethality, with epidemic outbreaks; some of them of historical character, like the one happened during the first half of the last century. The action of a group of doctors, pioneers in clinical, research and teaching aspects, together with the health personnel that constituted their team, immersed in a successful public health policy, allowed to consolidate the necessary care of the sick child of this serious pathology, as well as many others, thus enabling the development of a structured and scientific proposal, in the light of the knowledge available at that time. Therefore, after 80 years, it is important to review the various clinical, pathophysiological and therapeutic aspects, in addition to the hospital and social context, of this successful history of the Chilean public health system.
\end{abstract}

Keywords:

Meningococcal disease; septic shock; pediatricians; pediatric history; epidemic

\section{Introducción}

Desde hace un siglo, datan en nuestro país las primeras referencias sobre enfermedades, probablemente, ocasionadas por Neisseria meningitidis; siendo en aquel tiempo reportado por el Dr. Cuevas, en la Sociedad Médica de Valparaíso, como meningitis cerebro espinal epidémica. Posteriormente, en 1923 el Dr. Casasbella comunicó el primer caso confirmado bacteriológicamente ${ }^{1}$.

En Chile, la epidemia de meningitis meningocóccica, la cual reportó 5.885 casos, con una letalidad del $16 \%$ y cuya máxima intensidad fue el segundo semes- tre de $1942^{2}$, motivó al Dr. J. Menenghello (1911-2009) y sus colaboradores a detallar, en forma muy precisa y rigurosa, los primeros casos clínicos de shock séptico (Sepsis meningocócica fulminante, Púrpura fulminante, Sindrome de Waterhouse-Friderichsen) ${ }^{3}$. Es destacable como los autores de la época (figura 1) planteaban oportunos comentarios e interesantes hipótesis, además de contundentes conclusiones, en relación a la evolución clínica, hallazgos de laboratorio y diversos aspectos de la terapia, los que aún podrían considerarse vigentes ${ }^{3,4}$.

En la actualidad, esta patología presentan una menor morbilidad residual, gracias a un exitoso trabajo
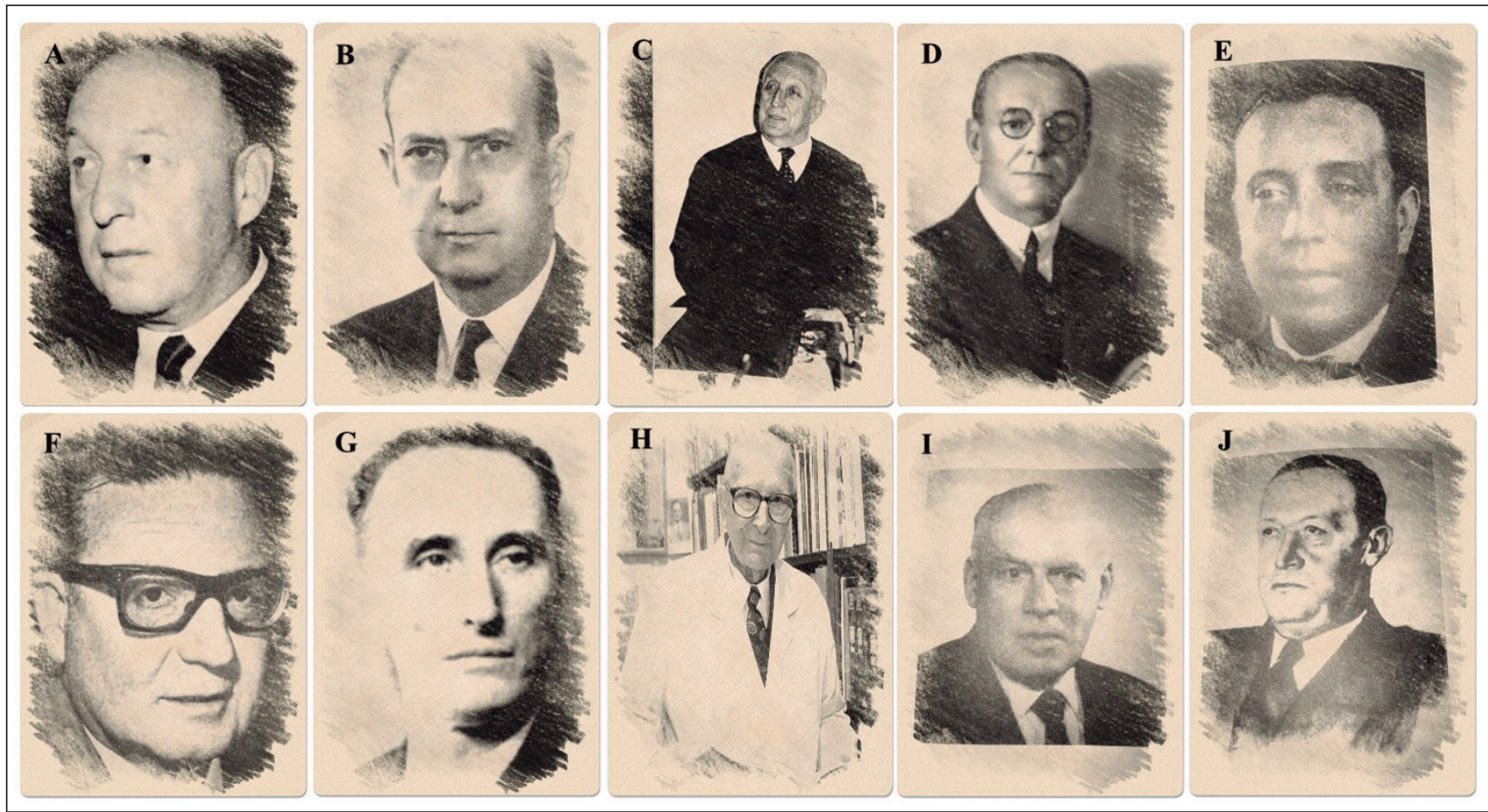

Figura 1. Diez médicos chilenos de relevancia para la consolidación de la pediatría nacional durante primera mitad del siglo XX. A. Dr. Adalberto Steeger (1903-1973); B. Dr. Aníbal Ariztía (1894-1986); C. Dr. Julio Meneghello (1911-2009); D. Dr. Luis Calvo Mackenna (1872-1937); E. Dr. Eugenio Cienfuegos (1885-1956); F. Dr. Salvador Allende (1908-1973); G. Dr. Eduardo Cruz-Coke (1899-1974); H. Dr. Héctor Croxatto (1908-2010); I. Dr. Julio Schwarzenberg (1891-1974); J. Dr. Arturo Scroogie (1894-1970). 
Figura 2. Meningococcemia. Lesiones purpúricas y equimóticas en pie y tobillo. Archivo Personal Fotográfico Dr. Alejandro Donoso.

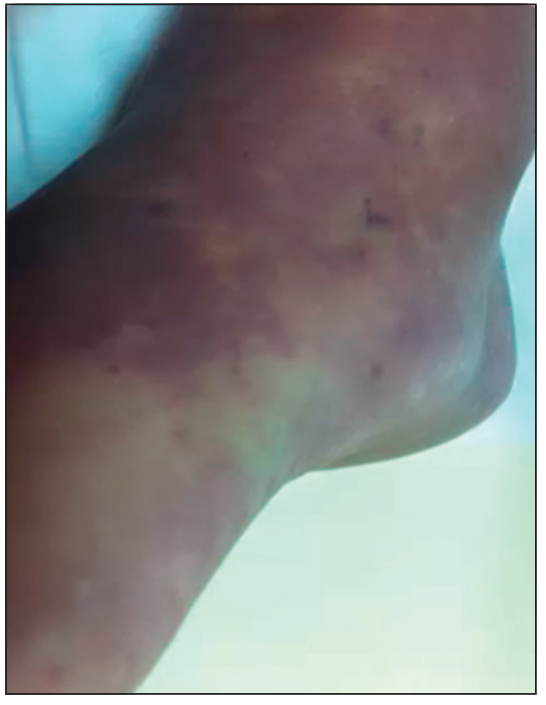

social-sanitario de carácter histórico, y específicamente, por el uso de sistemas de alerta precoz, medidas básicas de soporte vital y antibioticoterapia eficaz ${ }^{5,6}$. Parece interesante revisar desde una perspectiva temporal, teniendo en consideración el contexto científico y social de aquella época, el aspecto clínico con énfasis en la modalidad terapéutica empleada, para la cual ya han transcurrido ochenta años.

\section{Caso clínico ilustrativo}

Retroceda 80 años... Imagine un hospital nacional, a fines de invierno, al que ingresa un paciente con la siguiente historia:

"Niño de 3 años, que enferma bruscamente en la mañana con fiebre, anorexia rebelde y decaimiento; ocho horas después presenta vómitos pertinaces y dos horas más tarde se comprueba un punteado hemorrágico en la piel, que va aumentando en número y extensión y el cual se extiende como "aceite sobre la piel", junto con un progresivo agravamiento del estado general hasta llegar a la inconsciencia. El colapso vasomotor aumenta con cianosis, enfriamiento, pulso imperceptible y episodio de asfigmia ${ }^{i}$. A su ingreso se comprueba un niño en estado grave: púrpura intenso (figura 2), petequias de la mucosa bucal, aspecto marmóreo de la piel, pulso imperceptible, extremidades frías y cianóticas, fiebre de 39 grados. Kernig esbozado, otros signos meningeos no se encuentra, raya de Trosseau positiva $a^{i i}$. Signo de Gopperti presente".

Desaparición transitoria del pulso.

ii Raya meníngea o raya de Trousseau: línea eritematosa persistente trazada sobre la piel con la uña.

iii Midriasis de rápida instauración que se produce en los casos de meningitis epidémica cerebroespinal al estimular suavemente la piel
Se decide efectuar punción lumbar. (Basado en $\mathrm{H}$. Pumarino y V. Grossi 1942; J. Meneghello y cols, 1944. Rev. Chil Pediatr $)^{1,3}$.

\section{¿Qué se señalaba referente a la monitorización de los signos vitales?}

En los casos revisados, habitualmente, no se menciona la medición de la frecuencia cardíaca ni respiratoria ${ }^{1,3,7}$, sino que más bien, ocasionalmente, se describe en forma cualitativa y detallada el pulso. Asimismo, no se señalaba en los registros clínicos la medición de la presión arterial, a pesar que el esfigmomanómetro de mercurio fue creado en 1896 por Scipione Riva-Rocci (quién era internista y pediatra) (figura 3$)^{8}$. El médico ruso Nikoloai Korotkoff (figura 3) ideó la medición auscultatoria, siendo este un método más preciso'.

Tampoco se comenta sobre si se hubiera objetivado la diuresis, aunque en la mayoría de las oportunidades si se disponía de un examen de orina, como se comenta en los diversos reportes ${ }^{1,3,7}$.

\section{¿Cuáles eran los exámenes realizados?}

Aunque no corresponde enjuiciar los hechos del pasado con la información y conocimiento disponible en la actualidad, se puede apreciar que, generalmente, se realizaba raquicentesis, inclusive en pacientes en quienes estaría absolutamente contraindicada: "Después de la punción lumbar, la enferma se tranquiliza. A las pocas horas está sin pulso... y con psiquis totalmente abolida" ". En este caso, la autopsia reveló leptomeningitis purulenta con marcado aplanamiento de las circunvoluciones cerebrales ${ }^{7}$.

En aquella época los niños tenían dos punciones lumbares como mínimo (diagnóstica y control) e, incluso, en un $10 \%$ de ellos se efectuaba una tercera, siempre que la segunda muestra estuviese altera$\mathrm{da}^{10}$. No obstante, ya se recomendaba abandonar la segunda punción (en un paciente con mejoría clínica) dado que las características del líquido cefalorraquídeo (LCR) eran frecuentemente anormales, siendo entonces una práctica inútil que debiese ser "proscrita universalmente"10,11. La positividad del cultivo del LCR solo alcanzaba al 50\%, lo cual se atribuía a una técnica deficiente, como consecuencia de la demora entre la toma de la muestra y la siembra en aquellos pacientes que se hospitalizaban fuera de la horas de funcionamiento del laboratorio ${ }^{11}$; empero, durante el mismo año, la técnica se perfeccionó, realizando la siembra directa de la aguja de punción al medio de cultivo, aumentando el porcentaje de positividad por sobre el $80 \%{ }^{10,11}$. 


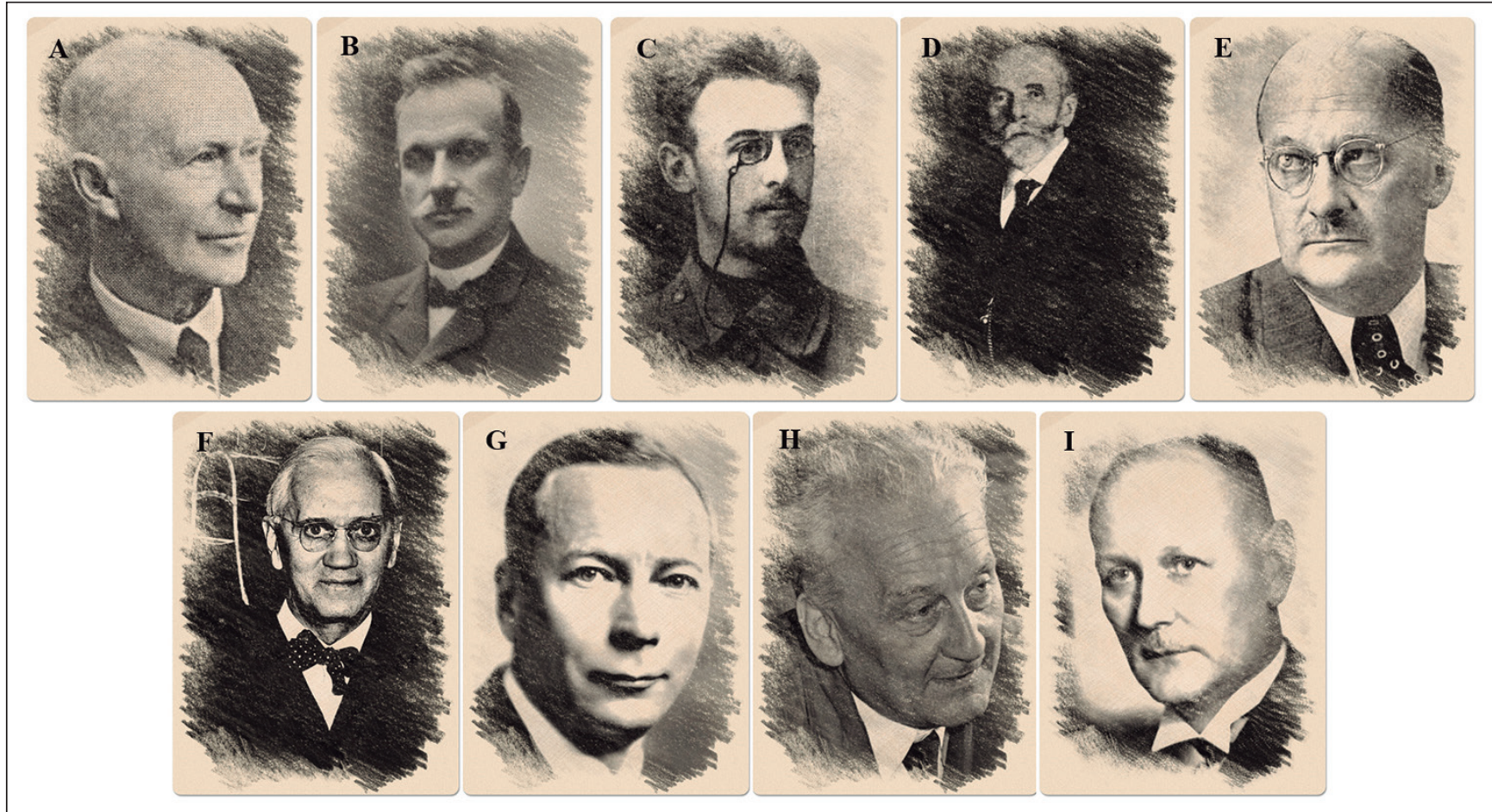

Figura 3. Ocho eminentes médicos y científicos del siglo XIX y XX en la historia de la medicina. A. Dr. Rupert Waterhouse (1873-1958); B. Dr. Scipione Riva-Rocci (1863-1937); C. Dr. Nikoloai Korotkoff (1874-1920); D. Dr. Heinrich Quincke (1842-1922); E. Adolf Windaus (1876-1959); F. Alexander Fleming (1881-1955); G. Henrik Dam (1895-1976); H. Albert Szent-Györgyi (1893-1986); I. Gerhard Domagk (1895-1964).

La factibilidad de la punción lumbar, en la práctica clínica, había sido establecida en 1893 por el médico alemán Heinrich Quincke (1842-1922) (figura 3) ${ }^{12}$ tanto para fines diagnósticos como terapéuticos, permitiendo esto último pavimentar el camino para la seroterapia intratecal a usarse en las próximas décadas.

El hemograma no era un examen realizado en todos los pacientes, sin embargo, en los casos analizados este no mostraba ninguna característica particular, siendo el hallazgo más frecuente la anemia. No se reporta el nadir leucocitario en las principales casuísticas de la época ${ }^{3}$.

\section{Sobre los signos de shock séptico y su fisiopatología}

Se mencionaba que el compromiso vasomotor y el colapso cardiovascular guardaban una estrecha relación con los síntomas "septicémicos" más que con los meníngeos". Se reconocían como signos de "shock septicémico": la alteración extrema de la temperatura corporal, inconciencia, polipnea superficial y la extensión del púrpura.

En cuanto a su fisiopatología, se postulaba con un rol relevante al aumento de los niveles sanguíneos de histamina (descubierta en 1907 por Windaus (figura 3) y Vogt, al sintetizarla a partir del ácido imidazol propiónico. Aunque se desconocía su existencia de forma natural, en 1910 se identificó su producción por el hongo cornezuelo del centeno) ${ }^{13}$, resultado del proceso inflamatorio infeccioso y de la que ya se conocía su efecto vasodepresor. De este modo, se atribuyó que las lesiones suprarrenales presentes en los pacientes con infecciones graves eran por la acción de los "venenos histamínicos". Se afirmaba que su origen provenía de las toxinas bacterianas que sensibilizaban al organismo, causando un incremento de la producción de histamina como también inhibición de la capacidad enzimática de la histaminasa, resultando en lo que se conocía como "shock histamínico". Este shock producía, por su acción inhibidora de la función cortico-suprarrenal, un grave desequilibrio electrolítico con la consiguiente reducción del volumen sanguíneo y, con la posibilidad de una mayor permeabilidad capilar ${ }^{14}$.

\section{¿Cuál era el tratamiento empleado en esa época?}

Pacientes, como los previamente comentados, eran tratados de la siguiente manera: respecto a la 


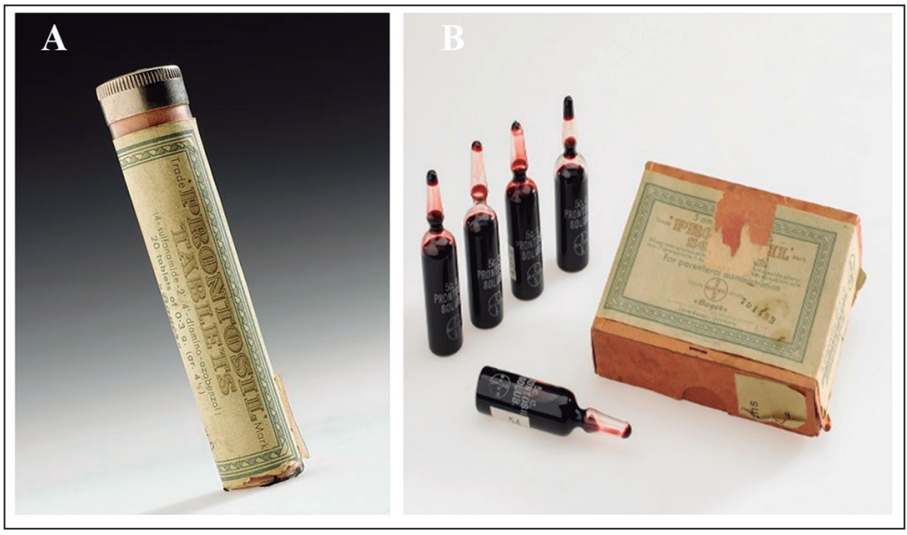

Figura 4. Primera "sulfa" Prontosi ${ }^{\circledR}$. A. Tubo de tabletas de Prontosil ${ }^{\circledR}$; B. Caja de ampollas de Prontosii ${ }^{\circledR}$. Museo de Ciencias, Londres.

hidratación esta se realizaba con "suero fisiológico o glucosado, según las necesidades". Además, se proponía la abundante administración de líquidos durante todo el día (agua de linaza ${ }^{\text {iv }}$, agua bicarbonatada), lo que tenía como objetivo disminuir el peligro de las complicaciones renales por el uso de sulfamidados (vide infra).

Luego, "Se inyecta un gramo y medio de sulfapiridina (Dagenan" Specia) en la vena y tónicos cardiovasculares". Esto se explica ya que, a pesar que la penicilina había sido descubierta por A. Fleming (1881-1955) (figura 3 ) en 1928, no fue hasta mediados de la década del 40 en que su uso se extendió significativamente ${ }^{15}$.

Igualmente, "Con el objeto de combatir el colapso periférico hemos usado coraminav, hormona cortical, extracto supra-renal, sin lograr el menor resultado"3.

Según lo comunicado por los doctores J. Schwarzenberg y J. Herrera, en alusión a 76 casos de pacientes hospitalizados durante la epidemia, con edades entre 2 meses y 12 años, el derivado de sulfamidados más usado era la sulfadiazina ${ }^{11}$. Esta se empleaba por vía oral; salvo que la existencia de vómitos, compromiso de conciencia o el trismo hiciese necesario usar la vía parenteral. La duración total del tratamiento variaba entre 5 a 15 días. En dicha casuística, la letalidad fue de $5,2 \%$, todas calificadas como forma clínica fulminante ("la que mata al enfermo antes que se haya producido una supuración meníngea u otra localización") y con una hospitalización de "pocas horas".

Como se aprecia el gran grupo de antimicrobianos disponibles en esa década eran "las sulfas". La primera "sulfa" de importancia clínica fue el Prontosil (sulfamidocrisoidina) (figura 4), sintetizada en Alemania por Gerhard Domagk (1935) (figura 3), solo siete años antes

\footnotetext{
iv Linum usitatissimum.

v Niquetamida, analéptico respiratorio y vasomotor.
}

de los reportes aquí revisados. Prontosil era un colorante industrial para lanas y cueros. Cabe señalar que por aquel tiempo existía la creencia de una relación entre la capacidad de teñir y la acción bactericida del fármaco ${ }^{16}$. Luego de comprobar su éxito, se dispuso de muchas sulfonamidas. La mayoría tenían buena absorción por vía enteral, mientras que su administración parenteral era difícil dado su carácter altamente alcalino ${ }^{17}$.

Es destacable que, ya en ese periodo, se efectuara la medición de la concentración en sangre y LCR del sulfonamido empleado. No obstante, este análisis era de poca trascendencia clínica, pues el resultado terapéutico era igualmente satisfactorio, independiente de la concentración sanguínea lograda, la que habitualmente era muy baja ${ }^{11,18}$.

Actualmente, el impacto de la terapia antibiótica precoz en el paciente séptico posee una evidencia contundente $e^{19-22}$. Sin embargo, durante la epidemia, el Dr. Pizzi ${ }^{2}$ comentaba que como medida destinada a disminuir la demora en el inicio de la terapia antibiótica el médico acudía al domicilio del paciente, para lo cual previamente se le había proporcionado transporte (automóvil) y un maletín, el cual entre otros insumos y fármacos contenía "sulfas" destinadas a usarse ante "la menor sospecha".

En relación al uso de antitérmicos, estos se empleaban cuando "las circunstancias así lo exigian" y en lo tocante a la fiebre, se señalaba: "La fiebre es un esfuerzo que hace la naturaleza para destruir los venenos y desechos, y de aquí que a veces se les permita a los fuegos vitales que ardan con fuerza; pero, a fin de que la fiebre no lo consuma todo, la naturaleza ofrece una compensación quitando el apetito, de modo que no se añada más combustible; aumentando la sed para ayudar a extinguir los fuegos..." "Es evidente, por lo tanto, que la fiebre es una protección contra la infección" 23 .

Para las manifestaciones purpúricas y/o hemorrágicas se recomendaba el uso de vitamina $\mathbf{K}$ (descubierta por el bioquímico danés Henrik Dam (figura 3) en 1929 al estudiar el efecto de la dieta hipograsa en pollitos recién nacidos). Esta fue sintetizada, por primera vez en Chile, por los doctores Eduardo Cruz-Coke y Héctor y Arnaldo Croxatto en el año 1939 en los laboratorios del Instituto Médico Técnico Sanitas ${ }^{24}$. Este se había creado, en una casona del barrio Brasil, en 1920 por el impulso de un destacado grupo de médicos profesores de la Facultad de Medicina de la Universidad de Chile, quienes guiados por un objetivo de bien público y sin fines de lucro, buscaban una mayor eficiencia médica.

Dentro de otras opciones terapéuticas también se proponía el uso de veneno de cobra, el que solo se menciona someramente. No obstante, la actividad protrombótica como también fibrinolítica (hemorraginas) del veneno de serpientes es conocida ${ }^{25}$. 
De igual modo, se planteaba el uso de vitamina C por vía intravenosa (100-200 mg/día) en búsqueda de un efecto antiinfeccioso y antitóxico, además de permitir una mejor tolerancia a la ingesta de los sulfamidados ${ }^{1}$. La vitamina $C$ fue aislada por el médico, fisiólogo y bioquímico húngaro Albert Szent-Györgyi (figura 3), quién identificó sus efectos biológicos (ácido hexurónico) desde el pimentón verde (1930). Por sus investigaciones y descubrimientos sobre el ácido ascórbico fue galardonado con el Premio Nobel de Medicina en 1937.

La seroterapia, mediante el uso del suero antimeningocócico (Instituto Bacteriológico de Chile), era recomendada diariamente, ya fuera por vía endovenosa, intraperitoneal o endolumbar, hasta que los signos tóxicos y hemorragias cesaran ${ }^{18}$. Sin embargo, no dio resultado, cediendo su paso a las "drogas químicas" 26 .

En esos años se utilizaba la "estimuloterapia” para el tratamiento de diversas enfermedades infecciosas, la cual consistía en una pequeña transfusión sanguínea o inyección intramuscular de sangre ${ }^{27}$. Su indicación estaba basada en la gravedad de la sintomatología y el esquema de administración propuesto era "día por medio" al inicio de la enfermedad y posteriormente con intervalos mayores, hasta la mejoría del paciente o la presencia de policitemia en el hemograma.

La sangre provenía del propio paciente o un pariente "muy cercano". En ocasiones, se asociaba con lactoterapia materna intramuscular. Dada la habitual dificultad de disponer de una adecuada vía venosa para transfundir al niño con "colapso circulatorio periférico" se recomendaba el uso previo de un baño caliente, ya fuera local o general ${ }^{28}$. La dosis variaba entre $5-10 \mathrm{ml} /$ $\mathrm{kg}$ de peso según la edad, y además el procedimiento mismo de la transfusión debía de ser "lento" $(<5 \mathrm{ml} /$ $\mathrm{min}$ ), por el riesgo de sobrecarga brusca para el trabajo cardíaco.

Cabe recordar que fue el Dr. A. Scroggie quien, en 1921, realizó la primera transfusión de sangre mediante hemoterapia intramuscular en un niño distrófico con el fin de "levantar la inmunidad"28. Luego de cuatro años, se comenzaron a efectuar transfusiones intravenosas en lactantes, sin determinación previa del grupo sanguíneo (pues estos eran incapaces de formar aglutininas específicas), inyectándose a presión en el seno superior, vía transfontanelar. Los resultados fueron malos y se abandonó esta modalidad. Recién en 1935, tres internos de medicina propusieron modificar la técnica y utilizar las vías venosas periféricas de las extremidades ${ }^{28}$.

En aquella se comentaba que la acción terapéutica de la transfusión era mecánica (incremento del volumen de sangre circulante), y, concomitantemente, se reconocía la importancia de los hematíes en el intercambio respiratorio, los elementos de la coagulación para la hemostasia, en el aporte de elementos nutritivos (acción trófica) como también en la función inmunitaria $^{28}$.

En la sección de actualidad de la Revista Chilena de Pediatría de 1950, en relación a las indicaciones de transfusiones sanguíneas ${ }^{29}$, se preconizaba el uso racional de las mismas. Además, se mencionaba la escasa utilidad de la transfusión de leucocitos en el niño con sepsis o del pobre beneficio de los factores inmunizantes en el plasma transfundido. Finalmente, se señalaba el incremento de la mortalidad observada al transfundir un paciente sin, previamente, corregir su hidratación. Esto debía anteceder al procedimiento 12 a 24 horas.

En la tabla 1 se resumen las principales opciones terapéuticas ocupadas.

\section{¿Cuál era la evaluación nutricional?}

Los Dres. J. Schwarzenberg y J. Herrera relataban que sus pacientes presentaban un pésimo estado nutritivo, originado por una prolongada alimentación deficiente y condiciones de higiene desastrosas ${ }^{11}$. Como respaldo a esta aseveración, durante los años de la epidemia, se señalaba que el niño proletario, "siempre se encuentra en un estado de hambre relativa" 30.

En las clases populares, al terminar el periodo de la lactancia materna, esta se sustituía por una dieta exclusivamente farinácea, como lo era la harina tostada de trigo, la que es carente de algunos aminoácidos esenciales (lisina y triptófano), generando un grave daño nutricional $^{31}$. Además, los niños no comían carne ni huevos ("artículos de lujo, solo al alcance de la gente adinerada"), como tampoco mantequilla, verduras y frutas. En suma, producto de las frecuentes infecciones enterocolíticas estivales, se producía una restricción crónica de alimentación láctea y sus derivados, la que podía durar hasta seis meses ${ }^{30}$.

En Chile, según el único censo del año 1936, la cantidad de leche para todo el país, alcanzó a 2.277,682 hectolitros, lo que representa 50.53 litros por habitante al año; sin embargo, al desglosar la leche destinada a la fabricación de mantequilla y queso, la cantidad de leche producida (fresca o industrial) alcanzaba solo a 73$93 \mathrm{ml} /$ día/habitante, constituyéndose en un alimento gravemente deficitario; más aún, considerando que la recomendación del Comité de la Liga de las Naciones era la ingesta de $1 / 2$ litro de leche al día en el menor de quince años ${ }^{30,32}$. Asimismo, la práctica de la alimentación natural era muy baja, lo que quedó plasmado en una encuesta del Seguro Obrero en la que se concluía que esta solo alcanzaba a un 30\% más allá de los tres meses de edad y solo un 7\% continuaba la lactancia por más de cinco meses ${ }^{32}$. 


\begin{tabular}{|c|c|}
\hline Tratamiento(ref) & Comentarios \\
\hline Antimicrobiano ${ }^{(2,11,16,17)}$ & $\begin{array}{l}\text { Uso de Sulfonamidas } \\
\text { Vía oral } \\
\text { Existía concepto de un uso precoz }\end{array}$ \\
\hline Hidratación/Fluidos de reanimación $n^{(3)}$ & $\begin{array}{l}\text { Hidratación según necesidades } \\
\text { Abundante aporte enteral }\end{array}$ \\
\hline Transfusiones de sangre $27-29)$ & $\begin{array}{l}\text { Uso frecuente } \\
\text { Distintas metas terapéuticas } \\
\text { Se proponía un uso racional de ellas }\end{array}$ \\
\hline Corticoides $^{(3)}$ & $\begin{array}{l}\text { Hormona cortical } \\
\text { Sin efecto benéfico }\end{array}$ \\
\hline Antitérmicos ${ }^{(23)}$ & $\begin{array}{l}\text { Uso según necesidad } \\
\text { Medidas físicas }\end{array}$ \\
\hline Sedantes ${ }^{(11)}$ & Uso según necesidad \\
\hline Fármacos con efecto vasoactivo(3) & $\begin{array}{l}\text { Administración de tónicos cardiovasculares como niquetamida } \\
\text { Hormona cortical } \\
\text { Extracto suprarrenal }\end{array}$ \\
\hline Analépticos(3) & Buscaban la estimulación del sistema nervioso central para tratamiento de la "deficiencia circulatoria" \\
\hline Vitamina $K^{(24)}$ & Uso ante manifestaciones purpúricas \\
\hline Vitamina $C^{(1)}$ & Uso por su efecto antitóxico y antiinfeccioso \\
\hline Suero antimeningocóccico ${ }^{(18)}$ & Sin ningún efecto benéfico \\
\hline
\end{tabular}

\section{¿Cómo era un Servicio de Pediatría?}

Esto se puede advertir en lo referido por el profesor Arturo Baeza Goñi sobre los resultados obtenidos bajo su dirección del Servicio de lactantes del Hospital Manuel Arriarán (figura 5) durante los años 1942 y $1943^{33}$.

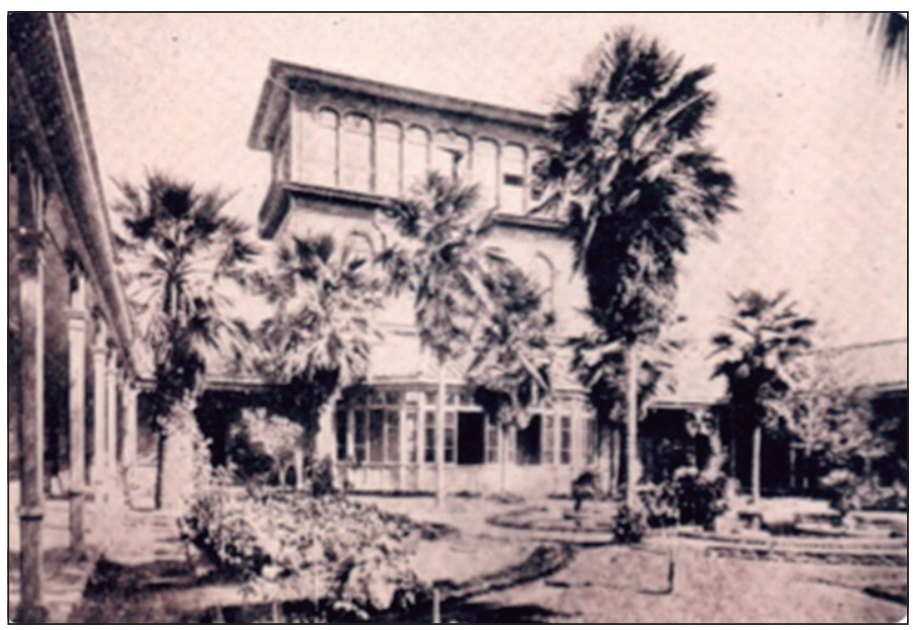

Figura 5. Hospital Manuel Arriarán. Vista del jardín y fachada interior de la casa principal de la familia Matte ubicada en calle Santa Rosa 1234. Este edificio fue destinado provisoriamente como el hospital mencionado (Proyecto patrimonio Sociedad Chilena de Pediatría. Autorizado por Dr. Nelson Vargas)
La cifra de mortalidad global era cercana a $25 \%$ y, de esta, $40 \%$ ocurría antes de 48 horas de ingresado ${ }^{33}$.

Al momento de su admisión, los niños se clasificaban en tres grupos (I, II, III), basado en un sistema "empírico e impresionista", que se realizaba con criterio clínico. El grupo I correspondía a niños con una adecuada nutrición, quienes desarrollaban morbilidad aguda. Si este niño fallecía, significaba una "falla evidente del servicio que lo ha atendido". El niño del grupo III $(60 \%$ del total) presentaba condiciones nutritivas deficientes de larga data, con varios días de enfermedad mal atendida en su casa, y cuya afección era muchas veces incurable, falleciendo a las pocas horas o días de ser hospitalizado. Se señalaba que "sobre un niño de tan mala calidad, el servicio no puede ser responsable del fracaso casi seguro y si llegara a sanar, el éxito revelaría un verdadero record de atención"33.

También, es interesante conocer los problemas suscitados por los niños con larga estadía hospitalaria, quienes eran abandonados por sus padres, y la dificultad para un pronto traslado a la Casa Nacional del Niño; además de las frecuentes infecciones intercurrentes, las que motivaban la prolongación de su hospitalización. Como solución se proponía el perfeccionamiento del sistema del Servicio de Atención Médica Domiciliaria, el cual ya estaba en marcha ${ }^{33}$. 


\section{Contexto sociosanitario a inicios del siglo $\mathrm{XX}$}

La cuestión social (1880-1920) $)^{34,35}$ originó, entre otros aspectos, una mirada crítica sobre la preocupante situación materno-infantil en nuestro país, en especial en lo concerniente a su mortalidad. Se debe tener en cuenta, que hasta inicios del siglo XX, la salud pública estaba fundamentada en instituciones que se sostenían gracias a la caridad cristiana ${ }^{36}$.

Ante esto, el esfuerzo político-sanitario transversal de las autoridades de la época, se orientó a la reducción de los elevados índices de morbimortalidad de la población. Así, las prácticas utilizadas para el control de la natalidad (aborto) y anticoncepción, como también el abandono y trabajo infantil, las malas condiciones sanitarias y de salud de los sectores populares, llamaron la atención de médicos e intelectuales, entendiéndose como las reales causas que impedían el desarrollo social y económico del país. Así, se estimularon ideas higienistas, que debían de ser asumidas por las instituciones estatales. Se promovió la enseñanza obligatoria de higiene en colegios fiscales, la vacunación obligatoria y el primer código sanitario (1918).

En la década siguiente, el Dr. Luis Calvo Mackenna publicó su histórica encuesta sobre mortalidad infantil (1930), mostrando una cifra de 231 por 1.000 nacidos vivos ${ }^{37}$. A raíz de esto, enfatizó en forma lúcida, la atención prenatal y el papel de la matrona en el equipo de salud ${ }^{31}$ siendo estas ideas refrendadas por el Dr. Víctor Grossi. Simultáneamente, el Dr. Eduardo Cruz-Coke creó la primera institución preocupada de la nutrición infantil, reconociendo así a la desnutrición como una condicionante trascendente de la mortalidad infantil.

El ministro de Salubridad del gobierno del presidente Pedro Aguirre Cerda (1938-1941), el Dr. Salvador Allende, publicó en 1939 el libro "La realidad médico-social chilena"38, donde representaba la mirada sanitaria que se aplicaría en esos años. Esta se fundamen- taba en un certero diagnóstico de las causas estructurales que ocasionaban la elevada mortalidad infantil. No obstante, como señala Rojas ${ }^{36}$, el Dr. Allende también identificó factores culturales. A modo de ejemplo, el $28 \%$ de los niños nacidos vivos eran ilegítimos y cuando se analizó el grupo de mortinatos, la presencia de esta condición ascendía al $48 \%{ }^{39}$.

Factores externos, como el terremoto de Chillán (1939), tuvieron un impacto evidente en las políticas sanitarias de los años siguientes. Básicamente, se evidenció la necesidad de unificar los servicios de salud, dispersos hasta la fecha, lo que a largo plazo dio origen al Servicio Nacional de Salud (SNS) en 1952, institución señera en el fomento y la protección de la salud materno-infantil ${ }^{40,41}$.

\section{Conclusiones}

Como se aprecia, el tratamiento del niño con shock séptico meningocóccico ha presentado cambios notables. Empero, algunos aspectos clínicos y principios terapéuticos conservan vigencia. Varios de ellos fueron descritos brillantemente, enunciados en comentarios exquisitos y consolidados en conductas exitosas, lideradas por un grupo de profesionales sanitarios. Esta patología, como muchas otras, es una de las beneficiadas por la gran historia del sistema de salud público chileno, labor efectuada por equipos de salud ejemplares y que cabe destacar y recordar.

Los autores agradecen al pediatra Dr. Nelson Vargas C., quien autorizó el uso de algunas de las fotografías del Proyecto Patrimonio de la Sociedad Chilena de Pediatría.

\section{Conflicto de intereses}

Los autores declaran no tener conflicto de intereses.

\section{Referencias}

1. Pumarino H, Grossi V. Aspecto clínico de los casos de meningitis meningocóccica que se presentaron en Valparaíso de 21 de mayo al 12 de septiembre de 1941 en la sección de niños del Hospital Deformes. Rev Chil Pediatr. 1942;13(1):3-20.

2. Pizzi M. A Severe Epidemic of Meningococcus Meningitis in Chile, 1941-1942. Am J Public Health Nations Health. 1944;34(3):231-8.

3. Meneghello J, Schwarz J, Steeger A: Sindrome de Waterhouse-Friderichsen. Rev. Chil. Pediatr. 1944;15(12):1010-23.

4. Pumarino H, Grossi V, Schonhaut L.
Aspecto clínico de los casos de meningitis meningocóccica que se presentaron en Valparaíso de 31 de mayo al 12 de septiembre de 1941 en la sección niño del Hospital Deformes. Rev Chil Pediatr. 2012;83(6):599-607.

5. Thompson MJ, Ninis N, Perera R, et al. Clinical recognition of meningococcal disease in children and adolescents. Lancet. 2006;367(9508):397-403.

6. Haj-Hassan TA, Thompson MJ, Mayon-White RT, et al. Which early 'red flag' symptoms identify children with meningococcal disease in primary care? $\mathrm{Br}$ J Gen Pract. 2011; 61(584):e97-104.

7. Simpfendorfer E. Consideraciones sobre casos de purpura fulminante. Síndrome de Waterhouse-Friderichsen. Rev Chil Pediatr. 1944;15(12):1027-33.

8. Benassi E. [SCIPIONE RIVA-ROCCI]. Minerva Med. 1963;54:3766-71.

9. James GD, Gerber LM. Measuring arterial blood pressure in humans: Auscultatory and automatic measurement techniques for human biological field studies. Am J Hum Biol. 2018;30(1).

10. Costa A, Álvarez C, Arcaya O, Montenegro A. El líquido céfaloraquídeo en la meningitis meningocócica de la infancia. Rev Chil Pediatr. 1943;14(11):803-17.

11. Schwarzenberg J, Herrera J. Algo más 
sobre meningitis meningocóccica. Rev Chil Pediatr. 1944:15(1):1-23.

12. González-Argote J, García-Rivero A, Dorta-Contreras A. El padre de la neuroinmunología. Neurol Arg. 2016;8(4):296-303.

13. Montes J, Flores J, Barrón E. Histamina, receptores y antagonistas. Rev Med Hosp Gen Mex. 2005;68(3):164-9.

14. Cienfuegos E. Deshidratación. Rev Chil Pediatr. 1942;13(11-12);1025-68.

15. Ledermann DW. La historia de la penicilina y de su fabricación en Chile. Rev Chilena Infectol. 2006;23(2):172-6.

16. Correa O. Actualidad Pediátrica. Rev Chil Pediatr. 1941;12(7):530-52.

17. Bentley R. Different roads to discovery; Prontosil (hence sulfa drugs) and penicillin (hence beta-lactams). J Ind Microbiol Biotechnol. 2009;36(6):775-86.

18. Steeger A. Experiencia clínica sobre ciertos agentes quimioterápicos en algunas enfermedades infecciosas de la infancia. II Tema: Quimioterapia en la infancia. Rev Chil Pediatr. 1942;13:13966.

19. Donoso A, Arriagada D, Cruces P, Díaz F. Shock séptico en pediatría II. Enfoque actual en el diagnóstico y tratamiento. Rev Chil Pediatr. 2013;84(6):606-15.

20. Davis AL, Carcillo JA, Aneja RK, et al. American College of Critical Care Medicine Clinical Practice Parameters for Hemodynamic Support of Pediatric and Neonatal Septic Shock. Crit Care Med. 2017;45(6):1061-93.

21. Kohn-Loncarica GA, Fustiñana AL, Jabornisky RM, et al. Red de Investigación y Desarrollo de la Emergencia Pediátrica Latinoamericana (RIDEPLA) How Are Clinicians Treating Children With Sepsis in Emergency Departments in Latin America?: An International Multicenter Survey. Pediatr Emerg Care. 2019 May 1.

22. Cruz AT, Perry AM, Williams EA,
Graf JM, Wuestner ER, Patel B. Implementation of goal-directed therapy for children with suspected sepsis in the emergency department. Pediatrics. 2011;127(3):e758-66.

23. Gentilini B. Terapéutica Especial. Explicación y terapéutica de la fiebre. En: Gentilini B, La Ciencia y el arte de la salud por la medicación natural (Fisioterapia), Santiago: Editorial Apostolado de la Prensa, 1919; 204-207. Disponible en http://www.memoriachilena.gob.cl/ archivos2/pdfs/MC0059623.pdf. Última visita 05-11-2019.

24. Bustamante W. Vitamina K. y sus aplicaciones en Pediatría. Rev Chil Pediatr.1941;12(1):47-54.

25. de Roodt A, Estévez-Ramírez J, PaniaguaSolis J, et al. Toxicidad de venenos de serpientes de importancia médica en México. Gac Med Mex. 2005;141(1):1321.

26. Romero H. Anotaciones sobre meningitis meningocócica. Rev Chil Pediatr. 1943;14(1):14-7.

27. Vargas N. El Siglo XX. En: Vargas N: Historia de la pediatría chilena: Crónica de una alegría, Santiago: Editorial Universitaria, 2002;71-141.

28. Leiva H, Schepeler M. Experiencia sobre transfusión de sangre en pediatría. Rev Chil Pediatr. 1941;12(5):386-423.

29. Correa O. Transfusión sanguínea. Sus indicaciones. Rev Chil Pediatr. 1950;21(3):125-8.

30. Scroggie A. Síndrome policarenciales en la infancia. Rev Chil Pediatr. 1942;13(1112):945-1024.

31. Jiménez de la Jara J. Políticas de Salud Infantil en Chile. En: Jiménez de la Jara J. Angelitos Salvados. Un recuento de las políticas de salud infantil en Chile en el siglo XX, Santiago: Editorial Uqbar, 2009;63-94.

32. Scroggie A. El problema de la leche. Rev
Chil Pediatr. 1942;13(10):863-8.

33. Baeza A. Comentarios sobre la estadística del servicio de lactantes del hospital Manuel Arriarán. Rev Chil Pediatr. 1944;15(4):290-6.

34. Grez S. La cuestión social en Chile: ideas y debates precursores: (1804-1902)/ recopilación y estudio crítico de Sergio Grez Toso. 1a. ed., 1a. reimpr. Santiago de Chile: DIBAM, 1997. 577 p. Disponible http://www.memoriachilena.gob.cl/602/ w3-article-73559.html, última visita 1711-2019.

35. Orrego Luco A. La cuestión social. Disponible en http://www. memoriachilena.gob.cl/602/w3article-8825.html. Última visita 17-112019.

36. Rojas J. Cuarto período, 1920-1950. La infancia y el estado de bienestar. En: Historia de la infancia en el Chile republicano, 1810-2010, Santiago: JUNJI, 2010;325-480. Disponible en https:// www.aacademica.org/jorge.rojas.flores/9, última visita 19-11-2019.

37. Schonhaut L. La Mortalidad Infantil en Chile estudiada por la Sociedad de las Naciones. Rev Chil Pediatr. 2007;78(2):202-10.

38. Allende Gossens, S. (1939). La realidad médico-social chilena. Disponible en https://doi.org/10.34720/mj3z-6m24, última visita 21-11-2019.

39. Allende Gossens, S. (1939). La realidad médico-social chilena (síntesis), Imprenta Lathrop, Santiago, 1939, p. 77. Disponible en http://www.memoriachilena.gob. cl/602/w3-article-7737.html, última visita 21-11-2019.

40. Valdivieso R, Juricic B. El sistema nacional de salud en Chile. Bol. Oficina Sanit Panam. 1970;68(6):478-85.

41. Hevia P. Servicio Nacional de Salud de Chile: Estructuras y funciones. Pediatría (Santiago) 1970;13:81-5. 